\title{
UM JOGO ENTRE CAPOEIRA ANGOLA E ANTROPOLOGIA TEATRAL ${ }^{1}$
}

\section{A game between Theatrical Anthropology and Capoeira Angola}

\author{
Renata de Lima Silva \\ José Luiz Cirqueira Falcão \\ Universidade Federal de Goiás - UFG
}

Resumo: A Antropologia Teatral, um campo de estudo da presença física e mental do ser humano em situação de representação, conforme definição de Eugenio Barba, analisa um conjunto de princípios que dilatam a presença. Nesse artigo, esse campo, consolidado no Teatro, é explorado como possibilidade de interpretação da prática da Capoeira Angola, uma manifestação cultural criada por africanos e seus descendentes no Brasil. Em uma provocação lúdica, com a utilização de uma personagem ficcional, construímos um jogo analítico com o propósito de extrapolar as noções de pré-expressividade e energia para além do corpo, levando em conta elementos da cultura, especialmente, da cultura negra.

Palavras-chave: Antropologia Teatral; Capoeira Angola; Pré-expressividade; Performance; Ritual.

\begin{abstract}
Theatrical Anthropology, a field of study of the physical and mental presence of human beings in situations of representation, as defined by Eugenio Barba, analyzes a set of principles that expand presence. In this article, this field, consolidated in the Theater, is explored as a possibility of interpreting the practice of Capoeira Angola, a cultural manifestation created by Africans and their descendants in Brazil. In a playful provocation, with the use of a fictional character, we built an analytical game with the purpose of extrapolating the notions of pre-expressiveness and energy beyond the body, taking into account elements of culture, especially black culture.
\end{abstract}

Keywords: Theatrical Anthropology, Capoeira Angola, Pre-expressivity, Performance, Ritual.

\footnotetext{
1 Este artigo é resultado de pesquisa que contou com o apoio financeiro do Conselho Nacional de Desenvolvimento Científico e Tecnológico - CNPq (Brasil), por meio do Edital MCTIC 28/2018
}

João Pessoa, V. 11 N. 2 jul-dez/2020

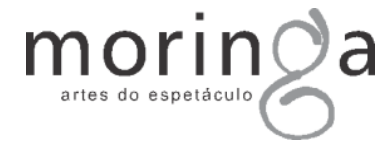




\section{Mas afinal Antropologia Teatral é Antropologia ou é Teatro? ${ }^{2}$}

Eugenio Barba definia, já em 1988, o que é a Antropologia Teatral, no prefácio do seu "A Arte Secreta do Ator - Dicionário de Antropologia Teatral, livro dedicado a "desvelar" alguns dos fundamentos da arte do ator/performer. Para o seu fundador, a Antropologia Teatral seria o estudo do comportamento do ser humano em situação de representação. Assim, Barba define a sua Antropologia Teatral como "o estudo do comportamento do ser humano que utiliza sua presença física e mental em uma situação de representação organizada segundo princípios que são diferentes daqueles da vida cotidiana" (BARBA, 2012, p. 13). Com isso, investigou a anatomia do processo de atuação, para a construção de um conhecimento prático estruturante das técnicas de interpretação sejam em culturas tradicionais ou no trabalho teatral contemporâneo.

Nesse entendimento, para Barba, "não se trata de compreender a técnica, e sim os segredos da técnica, que é preciso possuir para superá-la" (BARBA, 2012, p. 13). Essa sistematização transcultural, que superaria o conhecimento particular de cada prática artística, nunca havia sido realizada dessa maneira, pois não apenas se dava a conhecer agora os bastidores do atuar, mas o conhecimento das técnicas que garantiam a expressividade, chamadas por Barba de "préexpressivas".

É nessa linha que a obra "A Arte Secreta do Ator" envolve não apenas o entendimento do trabalho do(a) ator/atriz em suas formas e estudos "tradicionais", mas também processos corporais e treinamentos existentes que perpassam manifestações como as artes marciais, a Dança Balinesa, o Balé Clássico, o Butoh, - Balé Russo, as Touradas, os desenhos animados e os esboços gráficos de Michelangelo e de Rodin.

Barba e Savarese, em distintas edições de suas obras, procuraram elementos em comum entre as diversas técnicas conhecidas da arte da performance em diferentes lugares do mundo, com o objetivo de entender um

\footnotetext{
${ }^{2}$ Agradecemos as contribuições do Prof. Dr. Robson Corrêa de Camargo, da Universidade Federal de Goiás (UFG), para as nossas formulações sobre a Antropologia Teatral e a mestranda em Performances Culturais, Jordana Dolores Peixoto, pela cuidadosa revisão.
} 
comportamento "pré-expressivo" comum vivido em diferentes países, culturas e formas teatrais. Empreenderam uma busca pela "essência" da expressividade do artista cênico, ou seja, por um substrato comum a todas as formas artísticas e culturais da cena.

Assim, a Antropologia Teatral confronta e compara técnicas de atores/atrizes e dançarinos/dançarinas, em uma pretensa transculturalidade e, por meio do estudo do comportamento cênico, revela certos princípios que germinam a, denominada, pré-expressividade (BARBA e SARAVESE, 2012).

A partir do entendimento de que a vida cênica necessita de algo básico, vital, para se manter viva, os autores afirmam que há uma determinada energia que apoia a superação da cotidianidade, isto é, que engendra ao corpo humano o status de arte. Nessa busca, Barba chega a compreensão da energia, vida, poder ou espírito como noções traduzidas de palavras japonesas ki-hai, kikoro, io-in, koshi, ou de palavras balinesas taksu, virasa, bayu, chikara ou ainda de palavras em sânscrito prana e shakti ou as chinesas shun toeng e kung-fu.

Neste contexto, kung-fu, por exemplo, que se define como uma arte marcial, entre seus muitos sentidos, significa, para Barba, também uma qualidade especial que faz o artista vibrar e atingir o estado de presença, o que indica que domina todos os aspectos técnicos de seu trabalho.

Em diálogo com Barba e Savarese, podemos dizer que esse kung-fu, entendido como uma energia que supera, também está presente no jogo da capoeira, que, na qualidade de jogo-dança-luta, dispõe tanto de um acervo de códigos e movimentos, como de procedimentos próprios, que no momento do roda, onde a capoeira acontece em sua plenitude, precisam ser superados no sentido de gerar, nos corpos que jogam, um estado de autonomia e disponibilidade criativa que estão para além da racionalidade e da repetição.

A despeito de seu potencial de contribuição para a Antropologia Teatral, a capoeira é citada apenas ligeiramente na edição de 2005, numa demonstração realizada pelo bailarino e ator Augusto Omolú (1963-2013) e por Jairo da Purificação na International School of Theatre Antropology (ISTA), em 1996, em Copenhagen. A capoeira é apresentada como uma "luta dança" (fighting dance) de 
negros africanos escravizados no Brasil, que se torna também, posteriormente uma forma artística (BARBA e SAVARESE, 2005, p.232).

Não que a cultura afro-brasileira fosse desconhecida de Eugenio Barba, pois Omolú foi membro colaborador da ISTA desde o ano de 1993 até sua trágica morte em 2013, tendo protagonizado inclusive um espetáculo, Ur-Hamlet (2003), no qual Omolú, também dançarino de formação clássica, mestre nas danças afrobrasileiras, utiliza muitos de seus conhecimentos sobre os Orixás.

Embora Omolú fizesse parte da ISTA, a capoeira, pelo que pudemos verificar, não está inserida nos textos reflexivos desta publicação sobre a Antropologia Teatral, mas apenas em uma fotografia na sessão artes marciais e teatralidade no ocidente, no capítulo pré-expressividade, da segunda edição norteamericana deste livro. Há também um vídeo de 1996, de Augusto Omolú no Youtube, apresentando a capoeira e a dança dos orixás na ISTA.

Conforme exposto, a Antropologia Teatral trata dos princípios físicos e mentais do ser humano em performance, comportamentos distintos daqueles que se colocam em nossa vida cotidiana. Nesse campo do conhecimento, estudam-se fenômenos a partir da interculturalidade de diferentes formas como o Kathakaly indiano ou o Teatro Noh japonês, ou ainda várias danças como o Odissi indiano e as Danças Balinesas, passando pela biomecânica de Meyerhold, as ações físicas de Stanislavski e seus seguidores, Grotowsky, com estudos sobre a Ópera de Pequim.

Esta consciência do corpo do(a) atuante em situação de apresentação ou de representação foi definida por Barba e Savarese (1988) como técnica "extracotidiana. Esta é pautada na ideia de que uma forma particular e específica de utilização do olhar, do movimento, do corpo que, quando aplicada a fatores fisiológicos como direção dos olhos, equilíbrio, oposição entre a força gravitacional e o uso da coluna vertebral, deslocamento do peso-equilíbrio, resulta na potência da presença cênica do artista.

Segundo Barba e Savarese (2005, p. 5) a Antropologia Teatral não está preocupada com "a aplicação dos paradigmas da antropologia cultural ao teatro e a dança". Tampouco a definem como um campo de estudos do fenômeno 
performativo em culturas que são "tradicionalmente" estudadas pelos antropólogos. Com isso, Barba e Savarese isentam-se de um compromisso com a Antropologia, como um campo de estudo das Ciências Sociais, e afirmam seus esforços teóricos e práticos, a partir da ISTA, na compreensão da arte de atuar e de seu processo.

Embora Eugenio Barba tenha deixado claro em seus escritos o seu descompromisso com o sentido lato sensu da palavra antropologia, e a tenha utilizado estritamente para pensar o comportamento humano em situação de atuação e para a atuação, ele não deixou de receber sistemáticas críticas tanto sobre o emprego do termo antropologia e sua desconexão (ou mal uso) dos conhecimentos construídos no âmbito das Ciências Sociais, mas também por sua busca essencialista que pode ser interpretada como uma "anti-antropologia" ao ignorar a força e complexidade da cultura.

É nessa linha de raciocínio que Cauê Kruger (2008, p. 75) denuncia que apesar da Antropologia Teatral de Eugenio Barba gozar de ampla "repercussão mundial e ampla aceitação em inúmeras pesquisas na área de artes cênicas, não possui qualquer validade antropológica". Em sua crítica, o autor acima citado aponta, entre outros aspectos, como lócus problemático da teoria de Barba, a formulação da ideia de "pré-expressividade", por sua pretensa universalização de um "corpo-mente segundo técnicas extra-cotidianas" (BARBA, 1994, p.25). Nas palavras de Kruger (2008, p. 75):

Encontramos aqui o axioma central dos escritos de Barba, pois o conceito de "Antropologia Teatral" é definido como "o estudo do comportamento pré-expressivo do ser humano em situação de representação organizada" (Barba, 1994, p.24). O emprego dos termos aqui não é casual. Barba concebe a "pré-expressividade" como uma dimensão humana "universal", fisiológica e anterior a qualquer influência individual, social ou estética e, portanto, a teoria do teatrólogo se aproximaria de um obscuro "estruturalismo fisiológico".

Kruger (2008, p. 78) inda adverte:

[...] Mas devemos ir além e destacar o problema central da teoria de Barba: a aparente crença de que ao centrar sua 
preocupação teórica em uma dimensão "fisiológica" do uso do corpo em cena, no suposto nível universal "préexpressivo" e extra-cotidiano (e leia-se aqui anterior a qualquer significado cultural) este estaria "fora da cultura", fora do âmbito antropológico "convencional" e paradoxalmente, no cerne da "produção de sentido cênico". O autor acredita: "o teatro me permite não pertencer a nenhum lugar, não estar ancorado a uma só perspectiva e permanecer em transição" (Barba, 1994, p. 22).

Sem ignorar ou mesmo desconsiderar as críticas à proposta de Eugenio Barba e os limites de sua Antropologia Teatral, no que tange ao relativismo necessário para um pensamento antropológico, reconhecemos o seu esforço datado de "desvelar" a arte secreta do(a) ator/atriz encarnada no corpo e implicada na cena de distintas manifestações performáticas que atravessam fronteiras regionais e continentais do Oriente e do Ocidente, o que sem dúvida trouxe grandes contribuições para o campo das artes da cena.

A curiosidade de Eugenio Barba pela diáspora africana nas Américas fica explícita em seu contato com Augusto Omolú e, também, na célebre entrevista com a coreógrafa e poetisa, afro-peruana, Victória Santa Cruz, no documentário Black and Woman, do Odin Teatret. Entretanto, a ausência da capoeira nas formulações da Antropologia Teatral nos instiga a pensar como a energia, os movimentos e a prática desta complexa manifestação afro-brasileira poderiam colaborar na reflexão sobre a arte da atuação.

Ao reconhecer o potencial da capoeira não apenas pelo suporte técnico e criativo para o trabalho do atuante (LIMA, 2002), mas por sua própria potência artística expressa no corpo, no jogo e na musicalidade no momento da roda de capoeira, nos colocamos, neste artigo, frente ao desafio de promover um jogo entre a Capoeira Angola e a teoria de Eugenio Barba, mais especificamente a partir da discussão sobre pré-expressividade, buscando com isso trazer à baila as "manhas do mandingueiro" à luz de um olhar atento para o corpo que as lentes do teatro e da dança podem oferecer, inclusive a partir dos estudos teatrais de Eugenio Barba.

\section{Jogo de angola tem dendê}


O canto corrido de Capoeira Angola: "Tem dendê, tem dendê, o jogo de angola tem dendê" (domínio público), faz referência ao azeite de dendê, um óleo extraído do fruto de uma palmeira, muito utilizado na culinária africana e afrobrasileira (inclusive em comidas ritualísticas oferecidas às divindades), para sugerir que o jogo de angola tem ingredientes muito especiais - a mandinga e a malícia.

Assim, colocando uma pitada de dendê nesse jogo-artigo, convidamos nossos leitores e leitoras a conhecerem a história de Zene, uma personagem ficcional criada a partir de experiências e encontros reais no contexto da capoeiragem. Com isso, almejamos, neste escrito, introduzir a Capoeira Angola para os não iniciados, considerando que as narrativas, no contexto das culturas afro-brasileiras e em especial da capoeira, constituem práticas frequentemente utilizadas pelos mestres e mestras como forma de transmissão de seus conhecimentos. Convém frisar que os aspectos metodológicos que conduziram esse estudo assentam sobretudo na experiência de mais de vinte anos com e na capoeira por parte dos dois autores e no desafio profissional de um deles em ensinar Capoeira Angola, numa perspectiva de valorização da cultura afrobrasileira. A partir de seu lugar de fala, procura criar, no campo das artes da cena, possibilidades pedagógicas, considerando também sua formação em Dança e também algumas experiências pontuais com o treinamento proposto pelo grupo teatral Lume, cujo criador, Luís Octávio Burnier (1956-1995), teve relações diretas com Eugenio Barba e, consequentemente, ter sido por ele influenciado.

Mesmo que a capoeira tenha sido registrada pelo Instituto do Patrimônio Histórico e Artístico Nacional (IPHAN), do Ministério da Cultura (MinC), desde 2008, como patrimônio cultural imaterial do Brasil (IPHAN, 2008), existem muitos brasileiros que desconhecem essa manifestação cultural e os seus principais fundamentos. Não seria de se espantar que uma artista da cena no Brasil, interessada em Antropologia Teatral tenha tido contato com o Kung-fu, o Katakali, - Odossi ou o Butô em busca da ampliação de sua presença cênica e não tenha ainda experimentado a potência artística do corpo na capoeira, embora esse tema já tenha sido explorado dentro e fora da academia, desde o Grupo Folclórico Viva 
Bahia, de Emília Biancardi Ferreira, que arrebanhou capoeiristas para o espetáculo e estimulou bailarinas/os a praticarem capoeira como forma de preparação corporal (FERREIRA, 2006).

A dificuldade de se conhecer a capoeira para além da camada da superficialidade se dá também pelo próprio desenvolvimento dessa prática corporal, que em um curto espaço de tempo (menos de um século) se multiplicou de maneira vertiginosa, ocupando diferentes espaços sociais e assumindo diferentes formas. Como um camaleão, a capoeira vem se adaptando a diferentes contextos. Em alguns espaços preserva sua identidade negra e ancestralidade africana e em outros passa por um intenso processo de embranquecimento, que parece ter sido inevitável para a sua sobrevivência e a sua aceitação pelas camadas privilegiadas da sociedade. Ironicamente, foram justamente as formas que tiveram a negritude da capoeira empalidecida as que se tornaram mais populares.

O desvelar da "arte secreta" da capoeira é uma tarefa cheia de armadilhas, dada a sua complexidade, polissemia histórica e diversidade de suas formas. Ademais, essa performance cultural já foi tema de inúmeros trabalhos acadêmicos de pesquisadores e pesquisadoras da área de ciências humanas, tais como Adriana Albert Dias (2006), Antônio Liberac Cardoso Simões Pires (1996, 2001), Carlos Eugênio Líbano Soares (1994), Frede Abreu (2005), José Luiz Cirqueira Falcão (2004), Júlio Cesar Tavares (1984), Letícia Vidor de Sousa Reis (1997) Luiz Renato Vieira (1990, 1995), Pedro Abib (2004), Rosângela Costa Araújo (2002), dentre outros, que se dedicaram a fundo a análise de dados e registros históricos, orais e/ou pesquisas etnográficas, e que, de certa forma, agora nos isentam da necessidade de, nesse curto espaço, recontar a história da capoeira para que possamos nos concentrar nas possíveis relações entre Capoeira Angola e a chamada Antropologia Teatral.

\section{A capoeira brasileira e a angolana angoleira}


Zene (nossa personagem ficcional) é uma angolana de Benguela que veio ao Brasil por intermédio de um programa de intercâmbio entre países lusófonos e se fixou em São Paulo para estudar. Embora o curso de Teatro the interessasse bastante, Zene estava ansiosa para conhecer o Brasil, as praias, as comidas, o carnaval e a capoeira. A estudante teve contato pela primeira vez com a capoeira quando visitava Luanda e numa feira de exposições assistiu uma exibição de um grupo de mais ou menos seis pessoas, dispostas em um semicírculo, que se revezavam entre bater palmas, tocar instrumentos e simular uma luta que a impressionou pelos movimentos rápidos e acrobáticos, com saltos e rodopios no ar. Os instrumentos eram um pandeiro e um outro, muito parecido com o que ela conhecia como Hungu, que inclusive seu avô tocava. A luta, que também parecia um jogo, ou uma dança, por causa do aspecto de brincadeira e do acompanhamento musical, era desempenhada com muita virilidade por rapazes jovens e atléticos que exibiam seus dorsos nus. Apesar da virtuosidade dos movimentos que os brasileiros faziam, Zene considerou que também poderia executar aqueles movimentos já que se considerava muito habilidosa para lutas e esportes em geral. Na ocasião não teve a oportunidade de conversar com os capoeiristas, nem obter maiores informações, apenas viu na calça dos rapazes uma bandeira brasileira com a inscrição "Capoeira Brasil".

Anos depois, já no Brasil, recém-chegada em São Paulo, Zene parte em busca daquela manifestação que teria the chamado muita atenção na visita à Luanda. Ao pedir informação a uma colega de faculdade recebe a indicação de um local no bairro da Lapa. Zene telefona para o espaço indicado e recebe a informação que na quinta-feira, às dezenove horas, aconteceria a roda de capoeira e que essa seria uma boa oportunidade para uma visita.

No dia informado, Zene, ansiosa e com medo de se perder, chega ao local com uma hora de antecedência e por sorte o espaço já estava aberto. Chama a atenção da garota de Benguela o fato de estar escrito em uma placa, logo na entrada, "Centro de Capoeira Angola Angoleiro Sim Sinhô"3, pois, a não ser aquela

\footnotetext{
${ }^{3}$ O Centro de Capoeira Angola Angoleiro Sim Sinhô (CCAASS) foi fundado em 1993 por Mestre Plínio e é uma importante escola de Capoeira Angola da capital paulistana.
} 
experiência em Luanda anos atrás, Zene nunca tinha ouvido falar de capoeira em Angola.

Intrigada, a moça sobe as escadarias e no caminho se depara com muitos hungus pendurados na parede e, também, com muitas fotos que the pareceram ser de pessoas importantes. Ao chegar na sobreloja foi recebida com simpatia pelo rapaz que passava o pano no chão e que de pronto se apresentou como Chocolate ${ }^{4}$. O anfitrião abre um grande sorriso ao saber que a garota era de Angola e a convida para sentar, diz que o mestre ainda não tinha chegado, mas que eles iam conversando enquanto ele ia preparando o espaço para a roda, que estava programada para às dezenove horas... Dezenove e trinta no máximo.

Enquanto Chocolate terminava de passar o pano, Zene foi caminhando pela lateral da grande sala, olhando as fotos e imagens na parede. Chocolate, percebendo o interesse da moça, explica que são fotos de mestres antigos, considerados ancestrais e de outros mestres e capoeiristas ainda em atividade. Além das fotos, Zene repara também no quadro de Jesus Cristo e em pequenas estatuetas de santos católicos e de divindades negras, que ela pergunta quem são. O capoeirista, torcendo o pano de chão, diz que são orixás, deuses africanos cultuados no candomblé. Zene não os conhecia, mas imaginou que se tratavam de deuses dos lorubá.

Chocolate termina de limpar o chão e convida a visitante para sentar-se próxima dele enquanto afina a bateria, o conjunto de instrumentos utilizados na roda. A moça, um pouco encabulada, se aproxima. Chocolate pega um dos berimbaus dispostos na parede, tira a cabaça e estica o aço preso à verga para armar o instrumento. Zene comenta que em sua terra conhece esse instrumento como hungu e Chocolate começa a explicar que na roda de Capoeira Angola eles utilizam três tipos de berimbaus, o gunga, o médio e o viola. O gunga, com a cabaça maior, diz Chocolate, tem som mais grave e é responsável pela coordenação da roda, por isso, em geral, é tocado pelo mestre ou capoeiristas com mais experiência. O berimbau médio faz uma mediação entre o gunga e o viola, que é o instrumento de cabaça menor e de som mais agudo. Chocolate, com o viola na

\footnotetext{
${ }^{4}$ Treinel de Capoeira do Centro de Capoeira Angola Angoleiro Sim Sinhô.
} 
mão, demostra a maneira como faz repiques e firulas com o som, dizendo que se trata de um berimbau faceiro feito criança. Zene acha graça na metáfora.

O ponteiro do relógio se aproxima das dezenove horas e Chocolate se apressa, experimenta os pandeiros, pá pum pá, pá pum pá, sacudindo suas platinelas e avaliando que já estão afinados; bate as mãos no tambor, chamado atabaque, que fala grosso; e com um baqueta de madeira toca o agogô, um instrumento de metal formado por um duplo sino e de som bem agudo e, por fim, raspa o reco-reco, um cilindro de bambu com faixas entalhadas. Chocolate dispõe todos os instrumentos sobre um grande banco de madeira, sugerindo uma lógica de organização, da direita para a esquerda - reco-reco, agogô, pandeiro, gunga, médio e viola, o outro pandeiro e, por fim, o atabaque.

Suando e apressado Chocolate diz para Zene que vai deixar o carvão queimando para incensar o espaço e que na sequência vai tomar um banho. Zene acha estranho ele tomar banho para depois transpirar novamente, mas o capoeirista explica, enquanto acende o fogo em uma latinha com alguns furos, que estar de corpo limpo é importante para a energia da roda. E sai correndo para o banho.

Outros capoeiristas vãos chegando e vão para o vestiário se trocar, uma mulher chega com flores e as colocam nos altares dos santos. O Mestre Plínio ${ }^{5}$ também chega e acende algumas velas nos altares espalhados por todo o espaço. Nesse momento, Zene se sente confusa se estaria de fato em um espaço de capoeira como aquele que viu certa vez em Luanda. O mestre cumprimenta a africana com um largo sorriso e a abraça afetuosamente. Ao saber que Zene é de Angola vai logo explicando que essa capoeira, embora tenha esse nome é, na verdade, brasileira, criada por africanos no Brasil, entre eles muitos angolanos.

Zene se sente aliviada com a informação. Como assim, uma capoeira de seu país e ela nunca teria ouvido falar? O mestre acha graça no comentário da moça e joga um incenso em pó sobre a brasa do carvão, produzindo uma fumaça perfumada. O mestre, envolto na emanação, conta que o nome angola foi

\footnotetext{
${ }^{5}$ Plínio César Ferreira dos Santos fundou em 1993 o Centro de Capoeira Angola Angoleiro Sim Sinhô na cidade de São Paulo, onde vive e se dedica ao ensino da capoeira angola a partir de referências como Mestre Jogo de Dentro e Mestre João Grande.
} 
incorporado à capoeira para marcar a identificação com a ancestralidade africana, em um momento em que surgia na Bahia, a Luta Regional Baiana, depois chamada de Capoeira Regional, que era uma capoeira diferente da Angola.

E diante da fotografia de um homem velho, embaçada pela fumaça, diz que a Capoeira Regional misturou a capoeira tradicional com golpes de outras lutas marciais e que a Capoeira Angola fez o caminho inverso, foi buscar a raiz. E que aquele homem da fotografia, Mestre Pastinha, foi o seu grande protetor.

O mestre termina a defumação e pede licença para Zene e também vai se trocar. Chocolate volta à sala que já está cheia de capoeiristas vestidos uniformemente. A visitante observou que ninguém estava sem camisa ou descalço como tinha visto em Luanda. A informação sobre a existência de mais de uma capoeira fica ecoando na cabeça de Zene, que compreende que está em uma espaço em que se pratica uma capoeira diferente da que ela tinha visto. Nesse momento, Zene lamenta a confusão, pois de fato tinha gostado muito do que tinha visto e estava achando um pouco estranho as imagens de santos, o incenso... Integrante de uma família que se evangelizou, quando ainda era criança, a partir de um movimento missionário que se estabeleceu em sua região, Zene não tinha tido nenhum contato com outras formas de espiritualidade para além de sua religião. Apesar do incômodo, como já estava ali, resolveu esperar para conhecer a tal Capoeira Angola.

O mestre volta para a sala e os capoeiristas vão tomando assento na roda. Pouco a pouco, todos os instrumentos vão sendo apossados por tocadores. $O$ mestre saúda a todos os presentes e diz que a roda vai começar e que se trata de um ritual de celebração e vadiação, que depende de cada um que está presente para acontecer da melhor forma possível.

A palavra vadiação chama a atenção de Zene, mas o momento não parecia adequado para perguntas. O mestre, como quem capta o pensamento da visitante, diz que a vadiação é a brincadeira de angola, é a capoeiragem... Que é jogo, que é dança, mas que não deixa de ser luta e que por isso precisa de malandragem. Entende? Pergunta o mestre balançando o corpo em um gingado. Zene sorri e acena um sim com a cabeça, mas sem muita certeza se de fato compreendia. 
O mestre se concentra. As muitas vozes que se sobrepunham silenciam-se. O mestre faz o sinal da cruz e olhando para o teto cochicha algo com Deus e a resposta parece ser o soar do berimbau que toma conta da roda e de todo o espaço da sobreloja no movimentado bairro da Lapa. O mestre pergunta tocando forte no gunga, o médio logo responde e na sequência, bem serelepe, vem o viola repicando. Zene lembrou da explicação de Chocolate e sorriu. Os pandeiros também se apresentam. Mas o agogô, reco-reco e o atabaque permanecem calados. lêeeeeeeeee.... Entoa o mestre, anunciando a ladainha, o canto de abertura da roda. Com os olhos fechados, Mestre Plínio canta emocionado: Certa vez perguntaram a Seu Pastinha... O que era a capoeira...

Os dois rapazes que estavam aos pés da bateria, acocorados, abaixam a cabeça e escutam com a atenção o recado do mestre. Ao fim da canção, todos respondem em uníssono a última frase entoada: lê viva meu Deus, camará! Nessa toada, o mestre dá viva aos mestres, à capoeira, à Bahia... $A$ volta que o mundo deu e a volta que o mundo dá, sempre respondido pelo coro encorpado, da roda agora cheia, que repetia a frase do mestre e acrescentava o camará no final. Nesse momento, Zene repara que nenhum jogo se desenvolve no meio da roda e que todos estão absolutamente atentos ao canto.

Uma outra cantiga é entoada e os dois jogadores, ao pé do berimbau, depois de projetarem suas cabeças para o chão na direção dos tocadores, entram na roda, onde desenvolvem um jogo que começa lento e bem rente ao chão. Zene se impressiona com a capacidade dos jogadores de se movimentarem tão perto um do outro sem se esbarrarem e sem utilizar o apoio dos joelhos ou do quadril no chão, apenas as mãos, pés e cabeça. Os dois movimentavam-se como gatos e, em determinados momentos, dão botes feito cobras. O mestre continua a cantar e os participantes a responderem em coro, mas nesse momento eram cantos mais curtos do que aquele da abertura da roda. Zene observa com atenção o conjunto musical formado por todos aqueles instrumentos, quando uma grande gargalhada faz com que ela volte a sua atenção para jogo. Um dos jogadores se levanta rapidamente do chão e ambos sorriem, mas o jogo já não era o mesmo do início, parecia um pouco mais rápido e mais solto. A audiência estava agitada, como se 
torcesse para algo acontecer, mas o jogo se encerra e os dois capoeiristas voltam para perto do berimbau onde dão um aperto de mão e se abraçam para depois saírem da roda, cada um para um lado.

Outros tantos jogos se desenrolam naquela noite, com estilos diferentes, uns mais calmos, outros mais rápidos, uns de praticantes experientes e outros que pareciam novatos. Alguns jogos acontecem com maior risco e outros são inofensivos. No calor do momento, Zene viaja de volta para Angola, em vagas lembranças de um ritual que ouviu seu avô falar em sua infância, o N'Golo, em meio a uma celebração de puberdade em que os homens lutavam, simulando cabeçadas e coices das Zebras em disputa pela fêmea. Voltando à roda, a moça observou nos jogos, algo que chamou muito a sua atenção: um tipo de movimentação, que mais parecia uma dança de par, que depois veio a saber que eram as "chamadas de angola".

A roda se desenrola por duas horas sem interrupção, os jogadores vão se revezando nos instrumentos e a animação da audiência vai crescendo. Muitas cantigas são entoadas, alguma inclusive falando de Angola e em alguns momentos, Zene se emociona ao lembrar de sua terra. Por fim, todos os participantes, inclusive os tocadores que estavam sentados na roda, ficam em pé e são convidados pelo mestre a ir fechando mais a roda, até que fica um círculo minúsculo que Zene imagina não ser possível jogar ali dentro, mas eles jogam. A bateria nesse momento está alegre e agitada, mas ainda assim, Zene tem a impressão que o ritmo não é tão rápido quanto o que se lembra ter presenciado, anos atrás, no evento em Luanda.

O mestre encerra a roda com um lê seco e penetrante, diferente do lêeeeee do início que foi prolongado. As pessoas aplaudem e o mestre as convida para sentar para conversar um pouco. Ele agradece a presença de todos e apresenta convidados especiais: Mestre Gaguinho6 discípulo de Mestre Pastinha e Mestre

\footnotetext{
${ }^{6}$ Mestre Gaguinho (20/06/1935 - 24/08/2019) , baiano da Ilha de Itaparica, foi aluno de Mestre Pastinha e contribui com a capoeira paulistana frequentando rodas e fazendo importantes relatos.
} 
Moa do Katendê ${ }^{7}$, discípulo de Mestre Bobó ${ }^{8}$. Em seguida apresenta outros visitantes, capoeiristas de outros grupos que agradecem pela roda. - E você minha amiguinha de Angola? Essa é de Angola mesmo viu gente, legítima! Brinca o mestre. Zene, um pouco encabulada, diz que está muito admirada com o que viu, que foi ali buscar algo bastante diferente, uma capoeira com saltos e rodopios no ar e que nunca tinha ouvido falar em Capoeira Angola. A audiência ri e ela completa dizendo que estava muito emocionada, mesmo sabendo que a Capoeira Angola não é diretamente de Angola, mas que sentiu a presença de sua terra e de sua ancestralidade naquele momento. Zene agradece a todos dizendo que pretende voltar para praticar, que como ela é de Angola vai ficar boa nessa brincadeira. Volte mesmo, venha treinar! Venha ser uma angolana angoleira, diz o mestre.

\section{A "Arte secreta" da Capoeira Angola}

Essa história semi-ficcional, protagonizada por Zene, traz alguns elementos importantes pra se caracterizar o fenômeno da capoeira: 1) O fato de ter sido criada por africanos e seus descendentes no Brasil; 2) Apresenta as duas vertentes mais expressivas dessa cultura corporal, a saber a Capoeira Angola e a Capoeira Regional $^{9}$; 3) O fato de ser praticada em grupo e em determinados espaços (escola, academias etc.); 4) A presença do mestre e a relação mestre-discípulo; 5) A presença da musicalidade; 6) E, por fim, a caracterização do fenômeno da Capoeira Angola como prática que afirma sua identidade na ancestralidade africana, no ritual, na espiritualidade e na memória dos velhos mestres.

Zene, que de fato retorna para praticar e viver a Capoeira Angola naquele grupo, logo nos primeiros meses de experiência, pôde perceber mais alguns

\footnotetext{
7 Romualdo Rosário da Costa (Salvador, 29 de outubro de 1954 - Salvador, 8 de outubro de 2018), conhecido como Moa do Katendê, foi um compositor, percussionista, artesão, educador e mestre de capoeira brasileiro, considerado um dos mestres do CCAASS.

${ }^{8}$ Mestre Bobó (25/03/1924 - 08/07/1994), fundou a Academia de Capoeira Angola Cinco Estrelas, ensinou a capoeira no Dique do Tororó por mais de 50 anos tendo formado grandes capoeiristas como Mestre Moa do Katendê e Mestre Lua de Bobó.

${ }^{9}$ Embora a questão da Capoeira Contemporânea não seja abordada na história de Zene é importante que se diga que esta é uma vertente em que um número grande de grupos e praticantes se inserem, é uma prática que pode apresentar característica tanto da Capoeira Angola como da Capoeira Regional, mas não se define como nenhuma das duas, assumindo um constituição mais híbrida.
} 
aspectos que definem aquela abordagem de capoeira. Ao frequentar os treinos, as rodas e as conversas do ambiente daquela capoeira, compreendeu que o compromisso com os ensinamentos de Mestre Pastinha era uma constante. Isso por que, embora se reconheça a existência de linhagens de Capoeira Angola que não necessariamente se vinculem diretamente com a história e os ensinamentos de Mestre Pastinha, esse senhor que viveu entre 1889 e 1981, em Salvado-BA, sem dúvida, é uma importante referência.

Assim, a escola pastiniana ${ }^{10}$, como definiu Rosângela Costa Araújo (2004), contém alguns princípios, legitimados por seus praticantes, que delimitam o território da Capoeira Angola. Essa escola constitui a base, não somente para o ensino e a difusão dessa prática corporal, mas, também, os fundamentos filosóficos que orientam as condutas dos sujeitos para além da roda de capoeira. Sinteticamente, Araújo (2004) destaca que: a Capoeira Angola reafirma a história e a memória dos africanos e de seus descendentes no Brasil; a pertença grupal é extremamente importante na reflexão sobre o amparo e o fortalecimento dos saberes tradicionais; esses saberes constituem o eixo da formação de identidade baseada no pertencimento e no zelo à capoeira.

A mandinga e a malandragem, que Zene foi decifrando aos poucos, são os ingredientes especiais do jogo, que se adquirem com o treinamento e, sobretudo, com a experiência de roda. Tais conceitos são de difícil definição, mas são facilmente reconhecidos na roda.

Embora a malandragem e a mandinga, na capoeira, sejam frequentemente tratadas como sinônimos, aqui são compreendidas como noções correlacionadas e até mesmo análogas, mas não unívocas. Embora ambos os substantivos sejam femininos, apontamos a malandragem, metaforicamente, como algo de energia masculina e a mandinga, feminina. Isto é, potencialidades que se complementam,

\footnotetext{
${ }^{10}$ É importante frisar que Mestre Pastinha não criou a Capoeira Angola e que, embora seja o nome mais popular e reconhecido desse contexto, não é e nem nunca foi uma unanimidade. O livro "Jogo de discursos: a disputa por hegemonia na tradição da capoeira angola baiana", de Paulo Andrade Magalhães Filho, lançado em 2012, chama a atenção para a questão da tradição na Capoeira Angola, as tentativas de legitimação desta prática (como a criação de um centro representante da categoria e a participação em shows folclóricos), sua reascensão em meados dos anos 1980 e a disputa por espaço entre esta e outras modalidades da capoeira.
} 
tal como a dualidade filosófica taoista, yin e yang, duas forças opostas e complementares.

A malandragem, ao nosso ver, diz respeito ao mundo real e social. Trata-se da capacidade de driblar as adversidades da vida impostas sobretudo à população negra, como um comportamento social e corporal desenvolvido no espaço da rua, para se safar, com bom humor, das agruras da vida, como já discutiu o antropólogo Roberto DaMatta (1985). Por outro lado, a mandinga é algo que se desenvolve em âmbito interno, um segredo, um feitiço ou simpatias que agregam poder pessoal e que no contexto da capoeira emprega ao jogo um encanto, uma espécie de magia. Sim, as ideias aqui expostas sobre malandragem e mandinga, estão diretamente relacionadas também ao contexto do samba e do candomblé, respectivamente.

É razoavelmente fácil perder a elegância e se amofinar com um golpe bem dado ou mesmo com um camarada que "amarra" o jogo, isto é, não o deixa fluir. $O$ primeiro desafio do capoeira é se evadir da própria vaidade. Um jogo com malandragem é também aquele em que o jogador consegue sair dos golpes do adversário e contra-atacar no momento certo, com muita precisão, sem necessitar fazer uso da agressividade. Enquanto a mandinga está no "enfeitiçar" e no iludir o camarada e no encantar do jogo.

As chamadas de angola que fazem parte do jogo despertam a atenção por sua plasticidade e consiste, sinteticamente, em um momento do jogo em que um capoeira para em pé (às vezes agachado), de frente ou de costas para o outro jogador, com os braços abertos. O outro jogador deve "responder" à chamada aproximando-se, cuidadosamente, para não ser surpreendido porque o capoeira que chama poderá aplicar o golpe que desejar, caso o outro se aproxime sem o devido cuidado. Ao se encontrarem, ambos fazem deslocamentos sinuosos e matreiros para frente e para trás. Além de uma função estética, as chamadas de angola podem ser utilizadas para testar o conhecimento e a atenção do outro jogador e também para reorganizar a dinâmica do jogo.

Embora o jogo da capoeira consiste, ao nosso ver, numa dramaturgia corporal, composta pela combinação simultânea de golpes (ataques), defesas, floreios e as chamadas em situação de interação, isto é, de jogo, ele difere-se 
substancialmente de uma coreografia ou cena por seu caráter também agonístico, pois trata-se inegavelmente de uma disputa, na qual não se quer deliberadamente ganhar, mas que não se quer perder. Sobre isso, Zene ouviu de Mestre Plínio: "A gente tem que treinar não é para bater nos outros não... É para a gente não entrar na roda, tropeçar no próprio pé e sair falando que foi o outro quem bateu." ${ }^{11}$. Coisa que não acontece nem com o malandro porque é esperto, muito menos com o mandingueiro que está preparado, isto é, o/a angoleiro/a deve aprender a manipular as energias em seu favor. Assim, na prática, a performance do malandro não se distingue da do mandingueiro, daí essas noções aparecerem muitas vezes como sinônimo no contexto da capoeira.

Zene também observou que o nível dessa disputa pode ter graus muito variados, do tipo: só marcar os golpes (mostrar, mas não efetivar) ou então efetiválos levemente ou de forma mais contundente.

Zene é uma dessas que gosta de um jogo "pegado", quer dizer, com maior grau de competitividade e, consequentemente, de risco. O caráter agonístico do jogo de capoeira provoca uma empolgação na disputa que se faz presente não entre os jogadores, mas em todos os integrantes da roda, que vibram a cada lance. Essa empolgação tem seu ápice, por exemplo, quando uma rasteira é bem dada e não resta outra saída a não ser o chão.

Esse frenesi, da ordem da emoção e da espontaneidade, é em geral controlado pelo domínio técnico corporal adquirido por meio de treinamento capaz de fazer com que um violento golpe seja interrompido à uma fração de segundos das vias de fato. Outros elementos disciplinadores da conduta dos jogadores são a figura reguladora do mestre e a complexa estrutura da roda de capoeira que, por sua vez, dispõe de muitas normas e de uma ética própria.

${ }^{11}$ Frase proferida em diferentes ocasiões pelo mestre em treino de Capoeira Angola no Centro de Capoeira Angola Angoleiro Sim Sinhô, em São Paulo. 


\section{Capoeira Angola sob a perspectiva da pré-expressividade}

Como vimos, a Antropologia Teatral, como estudo empírico do trabalho do artista cênico, adota o conceito de pré-expressividade como fundamento. A construção do comportamento cênico, a partir de uma cultura corporal extracotidiana, potencializa a expressividade do corpo em cena, buscando um distanciamento da dimensão cotidiana em que as ações tendem aos automatismos e às domesticações. Nessa perspectiva, o comportamento cênico, construído na dimensão da extra-cotidianidade, tem como suporte técnico princípios básicos, como as ideias de oposição, equilíbrio e dilatação.

As questões da pré-expressividade apontadas na Antropologia Teatral de Eugenio Barba poderiam ser observadas na Capoeira Angola no seu contexto de "treino", como são chamados os momentos em que acontece a preparação/aprendizado e formação de conhecimento que se exercita na roda de capoeira. O treino, bem como o jogo da Capoeira Angola, constitui-se em um espaço de desafio, pois além de uma prática preponderantemente física, por vezes repetitiva e exaustiva, lida constantemente com o risco da queda e do golpe, o que exige do corpo um constante estado de alerta. Esse estado de alerta, ou "estar ligeiro", é a própria ampliação da percepção do corpo no espaço, que expande a presença do capoeirista, gerando prontidão. Na dança e no teatro esse conceito é discutido a partir da noção de presença. Embora o espaço do treino seja um espaço privilegiado para a preparação/aprendizagem para a roda, é importante considerar que a própria roda é também uma grande escola, como podemos observar em outras manifestações afro-brasileiras que não necessariamente têm um espaço formal de ensaio ou aprendizado, a não ser o próprio ritual. Aqui é importante ressaltar a potência do ritual como espaço de aprendizado estético já que é um espaço-tempo de sensibilidade dilatada.

É interessante observar que no final do século XIX e início do século XX, o espaço do treino da capoeira era menos formal. Não existia escola propriamente dita de capoeira, nem metodologias elaboradas para o ensino dos movimentos característicos. O movimento do corpo na capoeira retomava as técnicas e 
comportamento de situações do cotidiano e sobretudo do contexto do trabalho, já que estamos falando de uma construção cultural advinda da classe trabalhadora e escravizada. Um exemplo disso são os estivadores e pescadores, que contribuíram significativamente para a consolidação do que hoje chamamos de Capoeira Angola.

Por outro lado, essa associação da capoeira com o trabalho não poderia excluir um marcante comportamento corporal com origem num estilo de vida avesso ao mundo do trabalho - o da malandragem.

Nos estudos de Schechner (2002), o comportamento restaurado aparece como a própria possibilidade de "performação". São as ações físicas ou verbais preparadas e ensaiadas ou as que não estejam sendo exercidas pela primeira vez. "Pedaços" de comportamentos são recortados de um lugar e restaurados em outro, trazendo marcas não só de quem executa e restaura o movimento no próprio corpo, mas também das técnicas corporais que são normatizadas pela cultura. Schechner (2002, p. 29) afirma que "a maioria das performances, cotidianas ou não, tem mais de um autor. Rituais, jogos e performances da vida diária são escritos por um ente coletivo anônimo ou pela tradição".

Segundo Abreu (2005) o mundo do trabalho, assim como o da malandragem, tem especial penetração no universo da capoeira. Capoeiristas importantes para história da Capoeira Angola no século XIX, e início do século XX, em Salvador e no Recôncavo Baiano, tinham envolvimento direto com o trabalho no porto ou mar. Não por acaso, o mar é sempre poetizado nas canções de capoeira. "Foi na beira do mar; Foi na beira do mar; Aprendi a jogar capoeira de angola na beira do mar" (Canto corrido de Capoeira Angola, domínio público).

Dois exemplos dessa relação são: o pescador Samuel Querido de Deus, considerado como um dos mais afamados capoeiristas da Bahia - segundo contam, entre a década de 1930 e 1940 - e Mestre Pastinha (1889-1981), um dos principais líderes do movimento da Capoeira Angola, que, entre outras funções, trabalhou na estiva. Das técnicas de segurar, carregar e jogar sacos de cinquentas quilos ou mais, de equilibrar-se em canoas sobre o mar (funções em que o centro de gravidade do corpo desempenha papel fundamental) inevitavelmente contribuíram para a execução dos movimentos da capoeira e a evolução técnica dos mesmos. 
Embora a capoeira seja uma atividade extra-cotidiana, ela acontece no final do século XIX e início do século XX muito atada ao corpo do cotidiano dos trabalhadores que a jogavam como aponta Abreu (2005, p. 103-104):

A cocorinha. Eis aí outro cruzamento do mundo do trabalho do negro com a capoeira: a posição de cócoras em que os ganhadores ficavam (em repouso), às vezes horas a fio, como se não quisessem nada, desbastando o tempo, esperando a hora passar, adivinhando, intuindo, espreitando uma nova chance de trabalho. Torcendo para surgir um novo biscate, pois o trabalho do carregador (principalmente do ligado ao cais) também dependia do acaso, das flutuações da maré, do tempo das chegadas e saídas dos navios, da força da economia, a quantidade de carga disponível e de etc. $\mathrm{Na}$ beira do cais, enquanto a hora da labuta não chegava, podiam ficar esperando o relaxamento da vigilância policial para armarem rodas de jogos proibidos, cultuar vícios e iniciar vadiações.

A esses traços históricos e antropológicos da capoeiragem soma-se ainda o fato de que a capoeira escrava, antecessora da Capoeira Angola, já é em si uma restauração de comportamentos e memórias do processo da diáspora africana, já que a capoeira embora tenha clara matriz africana, foi criada, podemos dizer restaurada, em território brasileiro.

A discussão sobre comportamento restaurado de Richard Schechner (2002) e a história e prática da capoeira, vista aqui não apenas como uma manifestação que pode oferecer elementos para o trabalho do(a) atuante, mas como uma manifestação de arte propriamente dita, faz coro com os argumentos que denunciam a fragilidade da universalidade da ideia de extra-cotidiano segundo defendeu Eugenio Barba.

Evidentemente, nem todo capoeirista da época foi estivador ou saverista, no entanto, os exemplos de Samuel Querido de Deus e de Mestre Pastinha se justificam pelo fato de terem sido referências no mundo da capoeira, influências ativas na construção de uma cultura corporal que continuou sendo restaurada e reelaborada. A partir do CECA (Centro Esportivo de Capoeira Angola), criado em Salvador, em 1941, e também contemporaneamente a ele, escolas de Capoeira Angola começaram a surgir, modificando drasticamente o cenário contemporâneo 
dessa manifestação, que deixa de ser exclusividade da população socialmente marginalizada, e passa a ocupar diferentes espaços sociais e a movimentar uma economia da capoeira, que envolvem tanto a comercialização dessa prática como a sua profissionalização. O resultado disso, dentre tantos outros, é um alto desempenho técnico da performance do capoeirista, adquirido tanto a partir de uma maior intensidade e quantidade de treinamento, como a partir do surgimento de novas metodologias de ensino, somados a um incremento volumoso de informações com o advento da internet e das redes sociais.

\section{Oposições, equilíbrios e tensões}

Eugenio Barba observa e discute sobre tensões que obrigam o corpo a encontrar um novo ponto de equilíbrio como um modo de gerar a vida do(a) atuante, buscando nesse discurso um termo que substitua a palavra energia, alvo de centenas de mal-entendidos. Barba (1995, p. 11) afirma que, de fato "a vida do ator e do bailarino é baseada numa alteração de equilíbrio. Quando ficamos eretos, nunca estamos imóveis quanto parecemos estar; estamos de fato usando vários pequenos movimentos para deslocar nosso peso."

Nesse sentido, é interessante discutir como a ideia de energia aparece na performance da roda da Capoeira Angola e no corpo do capoeirista. Expressões como "a roda estava sem axé", "temos que manter o axé", "o axé da roda caiu", são frequentes na avaliação ou mesmo no desenrolar de uma roda de capoeira. A palavra axé, do ioruba àșe, que se torna presente na língua portuguesa falada no Brasil (tendo seu significado adaptado a diferentes contextos) é em princípio "a força que assegura a existência dinâmica, que permite o acontecer e o devir. Sem - axé, a existência estaria paralisada, desprovida de toda possibilidade de realização" (SANTOS, 2007, p. 39). Assim, axé está diretamente associado às noções de força, poder e vitalidade.

Evidentemente, o axé não é cultivado numa roda de capoeira da mesma maneira como acontece no candomblé, onde além de plantas e objetos ritualísticos, o sangue (sacrifício animal) exerce papel fundamental. No entanto, tanto no 
candomblé como na capoeira, o som percussivo e o canto são responsáveis por transmitir um poder de ação e de mobilização da atividade ritual que age sobre o corpo provocando um estado alterado - se não de consciência, de percepção.

Santos (2007) defende que o axé, na condição de força, pode diminuir ou aumentar, e que essas variações estão determinadas pela atividade e conduta ritual. Embora a capoeira e o candomblé sejam manifestações historicamente e culturalmente muito próximas - uma vez que se consolidaram como tal, no Brasil, no mesmo período (séc. XIX) e que eram, como por vezes ainda o são, praticadas pelas mesmas pessoas - elas são substancialmente diferentes. Contudo, ambas atuam sob a ótica de uma mesma cosmovisão, em que a energia, no caso o axé, é visto como algo físico, que deve ser cultivado.

$\mathrm{Na}$ Antropologia Teatral tem-se a conviç̧ão de que a pré-expressividade é o caminho que garante a presença e a vida do ator, tendo como principal objetivo o cultivar de uma energia por meio do treinamento. Esta atividade é a própria bios do(a) atuante, que é revelada por meio de uma tensão entre forças opostas, chamada por Eugenio Barba de o princípio da oposição. E quanto ao bios do corpo na capoeira? Onde reside a pré-expressividade do capoeirista?

A instalação do axé na roda de capoeira depende em primeira instância da musicalidade formada pela polifonia da bateria. Em outra instância, o jogo que acontece no centro da roda pode também movimentar o axé. A Antropologia Teatral sugere que a energia do(a) atuante é construída e intensificada na ampliação e ativação dessas forças, que agem no equilíbrio e nas oposições determinantes das dinâmicas dos movimentos, o que dilata a sua presença e consequentemente a percepção do espectador.

O equilíbrio como capacidade de se manter ereto é fruto de tensões musculares. Quando ampliamos o nosso movimento transferindo o peso para fora do eixo, esse equilíbrio básico é ameaçado, entrando em ação uma série de tensões para impedir a queda. Barba (1995) chama a atenção para essas tensões geradas em um equilíbrio instável, que exigem maior esforço, como fonte potente de expressividade. Na capoeira a questão do equilíbrio, visto de um ponto não apenas fisiológico mas também simbólico, merece lugar de destaque, pois ao 
mesmo tempo em que se brinca com isso na ginga e no jogo, o equilíbrio é tudo o que não se quer perder e, indubitavelmente, quanto mais o capoeirista tem domínio de seu equilíbrio, ao trocar "os pés pelas mãos" mais atrativo se torna seu jogo.

Se "o corpo do ator-bailarino revela sua vida ao espectador por meio de uma tensão entre forças opostas" (BARBA, 1995, p. 12), sendo este o princípio da oposição, na capoeira essa mesma lógica de tensão e oposição pode ser vista, física e metaforicamente, na relação do corpo do(a) angoleiro(a) com o chão. Ao mesmo tempo em que se quer evitar a queda e até mesmo que qualquer outra parte do corpo - a não ser as mãos, a cabeça e os pés - toque o chão, existe uma relação de intimidade com o chão, pois os movimentos devem acontecer preferencialmente do nível médio para baixo, uma vez que grande parte da performance de um(a) angoleiro(a) em jogo é feita com mais de dois apoios no chão. Não se quer o chão em uma queda, mas o chão é também um lugar de apoio e segurança.

Por outro lado, a densidade do movimento do(a) angoleiro(a) é constituída na ação de empurrar e de se enraizar no chão. Isto é, para se defender de um golpe o capoeirista vai ao chão numa negativa (defesa), em que o corpo fica totalmente paralelo ao chão, apenas com o apoio das mãos e pés; para sair da negativa e voltar em um ataque, o(a) capoeirista empurra o chão desprendendo suave ou repentinamente suas raízes. Por outro lado, a própria relação de ataque e defesa, que constitui o jogo, sugere relação de oposição, que também é de complementação. Uma defesa é uma oposição ao ataque, porém o equilíbrio de um jogo depende de um diálogo entre defesa e ataque em termos de complementariedade que implica uma alternância constante de ataques e defesas, ataques que se podem se converter em defesas e defesas que podem se converter em ataques.

Os corpos que gingam, brincando com seu próprio equilíbrio, têm nesse jogo de corpo sua principal base. Quase tudo no jogo de capoeira acontece a partir da ginga, ou na ginga. A oposição que se dá física e metaforicamente em relação ao chão também se aplica na relação entre os dois jogadores que se opõem e paradoxalmente se complementam. E quanto a tensão? Como essa noção se aplicaria a prática da capoeira? 
Bem, se olhássemos exclusivamente para o corpo do(a) capoeirista, como parece ser o interesse da Antropologia Teatral, veremos que para a execução de movimentos que exigem agilidade, força, leveza e equilíbrio é necessário um alto tônus muscular que está diretamente ligado à ideia de tensão, já que o corpo na capoeira abusa da elasticidade, no abrir e no fechar, no se expandir e no se encolher. Todavia, mais uma vez extrapolando as questões fisiológicas do corpo na prática da capoeira, podemos pensar a tensão que se estabelece no próprio jogo, pois como já mencionado, o caráter agonístico e o risco são eminentes no jogo e gera tanto um estado corporal como um estado emocional, que, por sua vez, pode aparecer tanto em forma de medo e insegurança nos jogadores menos experientes, como em forma de empolgação nos capoeiristas mais experientes que se excitam frente a desafios e riscos.

\section{Considerações Finais}

Depois de quatro anos no Brasil, Zene, nossa personagem ficcional, voltou para Angola, embora tenha apreendido muito em sua graduação em Teatro, considera que sua principal escola nesse período foi a Capoeira Angola. Isso porque além de desenvolver sua técnica corporal a partir dos equilíbrios, oposições e tensões que essa prática contempla em sua ginga, no "trocar os pés pelas mãos" e na relação com chão, Zene pôde aprender a lidar com as próprias emoções e vaidades dentro da roda de capoeira. A angolana era pequenina, mas era brava e não admitia levar a pior na roda. Quando tomava uma rasteira ou cabeçada queria logo revidar, mas com o tempo foi aprendendo as manhas do jogo por intermédio dos ensinamentos de Mestre Pastinha e de seus principais discípulos, bem como, pela voz dos mais velhos e das mais velhas de sua escola: "quanto mais o capoeirista é calmo, melhor é para o capoeirista", "escorregar não é cair, é um jeito que o corpo dá" e que "pra bater não precisa encostar".

Além disso, Zene destaca que incrementou suas aprendizagens sobre o teatro a partir de seu envolvimento com a Capoeira Angola, uma vez que ampliou 
a sua capacidade de jogo e de improvisação e desenvolveu habilidades musicais de cantar, tocar diferentes instrumentos e até de fazer pequenas composições.

Mas se tem uma coisa que, de fato, marcou Zene, foi a força ancestral que a Capoeira Angola é capaz de evocar. A aprendiz de mandingueira intrigava-se com o fato de ser a África, talvez Angola - o seu país, a matriz de tudo daquilo, já que se sentia familiarizada com alguns de seus elementos constitutivos, algumas particularidades da Capoeira Angola saltavam-Ihe aos olhos.

Com as aprendizagens adquiridas com/na Capoeira Angola, Zene pôde ampliar a sua formação como atriz, da mesma maneira que seus estudos sobre corpo e cena Ihe permitiram observar de forma mais aprofundada e alargada a roda de capoeira e perceber a potência artística daquele fenômeno.

A produção do conhecimento nas áreas das Ciências Humanas e das Artes demandam incorporações, bem como, articulações de perspectivas que ampliam, tencionam e jogam com possibilidades cada vez mais alargadas de compreensão dos fenômenos humanos e estéticos. Se, por um lado, a Antropologia Teatral proposta por Eugenio Barba, não dá conta das questões antropológicas, sem dúvida, atendeu a uma demanda datada no campo das artes da cena no que diz respeito ao estudo do corpo. Ademais, a lacuna deixada por Barba, foi há tempo preenchida por outras proposições, como é o caso da Antropologia da Performance, bem como o legado do encontro entre Victor Turner e Richard Schechner.

Hoje difundida no mundo inteiro, a capoeira constituiu-se, ao longo de sua trajetória histórica, num extraordinário campo de possibilidades exploratórias e tem sido investigada em cotejo com vários campos do conhecimento. Essa possibilidade de jogo entre a Capoeira Angola e os estudos no campo do Teatro se faz necessária, dada a potência e a abrangência que essa manifestação cultural adquiriu nas últimas décadas. No caso desse artigo, para construir, um jogo da relação entre a Antropologia Teatral e a Capoeira Angola foi preciso um pouco de malandragem para extrapolar as noções de pré-expressividade e energia para além do corpo, considerando os fenômenos da cultura, em especial, da cultura negra. 
Recebido em 07/01/2020

Aceito em 19/04/2020

\section{Referências}

ABIB, P. R. J. Capoeira Angola: cultura popular e o jogo dos saberes na roda. Tese (Doutorado em Educação) - Faculdade de Educação, Universidade Estadual de Campinas, Campinas, SP, 2004.

ABREU, F. J. Capoeiras - Bahia, séc. XIX: imaginário e documentação. Salvador: Instituto Jair Moura, v. 1, 2005.

ARAÚJO, R. C. lê viva meu Mestre - a Capoeira Angola da "escola pastiniana" como práxis educativa. Tese de doutorado. FE/USP: 2004.

BARBA, E. A canoa de papel: tratado de Antropologia Teatral. São Paulo: Hucitec, 1995.

BARBA, E. Prefácio: ISTA - International school of theatre anthropology. In: BARBA, E. \& SAVARESE, N. A arte secreta do ator - um dicionário de Antropologia Teatral. São Paulo: É Realizações Editora, 2012.

BARBA, E. \& SAVARESE, N. A Dictionary of Theatre Anthropology. The Secret Art of the Performer. Second Edition. New York: Routledge, 2005.

BARBA, E. \& SAVARESE, N. Anatomia del Actor - Un Diccionario de Antropología Teatral. México: Editorial Gaceta, 1988.

BARBA, E. Documentário Black and Woman (Eugenio Barba \& Victoria Santa Cruz). Disponível em https://www.youtube.com/watch?v=C2vnOa9isco\&gt ; Acesso em mar. 2020.

DAMATTA, R. A casa e a rua. São Paulo: Ed. Brasiliense, 1985.

DIAS, A. A. Mandinga, manha \& malícia: uma história sobre os capoeira na capital da Bahia (1910-1925). Salvador: EDUFBA, 2006.

FERREIRA, E. B. Raízes musicais da Bahia. Salvador: Governo da Bahia. 2006. GODARD, H. Gesto e Percepção. In: Lições de Dança 3. Rio de Janeiro: UniverCidade, 2003.

INSTITUTO DO PATRIMÔNIO HISTÓRICO E ARTÍSTICO NACIONAL - IPHAN. Certidão do registro no 7: Roda de Capoeira. Brasília, DF. 20 nov. 2008. Disponível em: $<$ http://portal.iphan.gov.br/uploads/ckfinder/arquivos/certidao_roda_de_capoeira.p df>. Acesso em: 05 nov. 2019.

KRUGER, C. Para além da canoa de papel. Cadernos de Campo. São Paulo, n. 17, 2008.

LIMA, E. T. Capoeira Angola como treinamento para o ator. Dissertação (Mestrado em Artes Cênicas). Universidade Federal da Bahia. 2002.

MAGALHÃES FILHO, P. A. Jogo de discursos: a disputa por hegemonia na tradição da capoeira angola baiana. Salvador: EDUFBA, 2012.

PIRES, A. L. C. S. A capoeira no jogo das cores: criminalidade, cultura e racismo na cidade do Rio de Janeiro (1890-1937). Dissertação (Mestrado em 
História). Campinas-SP, Instituto de Filosofia e Ciências Humanas, Departamento de História, Universidade Estadual de Campinas, 1996.

PIRES, A. L. C. S. Movimentos da cultura afro-brasileira: a formação histórica da capoeira contemporânea (1890-1950). Tese (Doutorado em História). Campinas-SP, Departamento de História, Universidade Estadual de Campinas, 2001.

REGO, W. Capoeira Angola: um ensaio sócio-etnográfico. Salvador: Itapuã, 1968.

REIS, L. V. S. O mundo de pernas para o ar: a capoeira no Brasil. São Paulo: Publisher Brasil, 1997.

SANTOS, J. E. dos. Os nagô e a morte. Petrópolis: Vozes, 2007.

SCHECHNER R. O que é Performance. In: O Percevejo. Rio de Janeiro: UNIRIO, 2002.

SILVA, R. L. A potência artística do corpo na Capoeira Angola. Ilinx Revista do LUME. Campinas: UNICAMP, n. 1, set. 2012.

SOARES, C. E. L. A negregada instituição: Os capoeiras no Rio de Janeiro (1850-1890). Rio de Janeiro: Secretaria Municipal de Cultura, 1994.

TAVARES, J. C. Dança da guerra: arquivo-arma. Dissertação (Mestrado em Sociologia). Brasília-DF, Departamento de Sociologia, UnB, 1984.

VIEIRA, L R. Da vadiação a Capoeira Regional: uma interpretação da modernização cultural no Brasil. Dissertação (Mestrado em Sociologia). BrasíliaDF, Departamento de Sociologia, UnB, 1990.

VIEIRA, L R. O jogo de capoeira: cultura popular no Brasil. Rio de Janeiro: Sprint, 1995. 